\title{
Energy Expenditure During Extravehicular Activity through Apollo
}

\author{
Heather L. Paul ${ }^{1}$ \\ NASA Johnson Space Center, Houston, Texas, 77058
}

\begin{abstract}
Monitoring crew health during manned space missions has always been an important factor to ensure that the astronauts can complete the missions successfully and within safe physiological limits. The necessity of real-time metabolic rate monitoring during extravehicular activities (EVAs) came into question during the Gemini missions, when the energy expenditure required to complete EVA tasks exceeded the life support capabilities for cooling and humidity control and crewmembers (CMs) ended the EVAs fatigued and overworked. This paper discusses the importance of real-time monitoring of metabolic rate during EVA, and provides a historical look at energy expenditure during EVA through the Apollo program.
\end{abstract}

\footnotetext{
${ }^{1}$ Insert Job Title, Department Name, Address/Mail Stop, and AIAA Member Grade for first author.
} 